\title{
GREENWASHING E A CERTIFICAÇÃO NO COMÉRCIO JUSTO E SOLIDÁRIO: CONSUMISMO E SUSTENTABILIDADE NA FORMAÇÃO DA SOCIEDADE TRANSNACIONAL
}

\section{GREENWASHING Y LA CERTIFICACIÓN DE COMERCIO JUSTO Y SOLIDARIO: CONSUMISMO Y SOSTENIBILIDAD EN LA FORMACIÓN DE LA SOCIEDAD TRANSNACIONAL.}

\author{
1'Joana Stelzer \\ ${ }^{2}$ Everton das Neves Gonçalves
}

\section{RESUMO}

O fenômeno do Greenwashing trouxe a discussão sobre consumismo, sustentabilidade e certificação. No Brasil, a legislação dos produtos orgânicos inspirou a Portaria MTE no 2.060 /2014 (Comércio Justo), que adotou três métodos de certificação: por auditoria, participativa e controle social. A possibilidade de produtor e consumidor serem partícipes desse processo fez emergir um sistema normativo que realiza os valores de uma sociedade transnacional. A pesquisa utilizou o método crítico indutivo, os meios foram majoritariamente bibliográficos, a legislação foi interpretada pelo método hermenêutico gramatical. Quanto aos fins, foi descritiva e explicativa.

Palavras-chave: Comércio justo, Certificação, Consumo responsável, Transnacionalidade

\section{RESUMEN}

El fenómeno del Greenwashing presento la discusión sobre consumismo, sostenibilidad y certificación. En Brasil, la ley de productos orgánicos inspiró la Portaría MTE n 2.060/2014, que adoptó tres métodos de certificación: auditoría, participativa y control social. La capacidad de los productores y consumidores actuar como participantes de este proceso ha dado lugar a un sistema legal que realiza los valores de una sociedad transnacional. La investigación hace uso del método crítico inductivo, los medios fueron en su mayoría bibliográficos, la legislación fue interpretada por el método hermenéutico gramatical. En cuanto a la finalidad, la investigación fue descriptiva y explicative.

Palabras-claves: Comercio justo, Certificación, Consumo responsable, Transnacionalidad

\footnotetext{
${ }^{1}$ Doutora em Direito pela Universidade Federal de Santa Catarina - UFSC, Santa Catarina (Brasil). Professora pela Universidade Federal de Santa Catarina - UFSC, Santa Catarina (Brasil). E-mail: contatojoana@ yahoo.com.br

${ }^{2}$ Doutor em Direito pela Universidade Federal de Minas Gerais - UFMG, Minas Gerais (Brasil) Professor de Direito pela Universidade Federal de Santa Catarina - UFSC, Santa Catarina (Brasil).

E-mail: evertong@ vetorial.net
} 


\section{Introdução}

O Greenwashing (anglicismo que indica apropriação indevida de virtudes de proteção ambiental por parte dos produtos e suas respectivas organizações) é uma prática publicitária não ética que consiste em fazer o consumidor acreditar em uma prática sustentável que inexiste. O fenômeno resulta de duas práticas emergentes: o consumismo e a consciência ambientalista. Vale dizer, por um lado, verificou-se o anseio de aquisição desenfreada, por outro, afirmou-se a consciência de manutenção do meio ambiente. $\mathrm{O}$ mercado (especialmente por intermédio do greenmarketing) logo tratou de oferecer produtos ditos certificados, ou seja, que teriam o condão de assegurar ao consumidor uma série de produtos que não trouxessem danos (ou que trouxessem menos danos) à convivência da pessoa humana e seu entorno. Determinadas organizações igualmente se especializaram em fazer as certificações verdes e se arvoraram em autoridades legítimas para a emissão de selos. Dessa realidade surgiram distorções: pequenos produtores pagando caro para certificar os produtos, corrupção nos processos de auditoria ou mesmo uso indevido de selos que nada asseguravam.

Iniciativas bem diferentes das certificações tradicionais, contudo, surgiriam, como selos nos quais houvesse a participação ativa de produtores e consumidores. Tal fenômeno passaria a retratar valores de uma coletividade que transborda as fronteiras nacionais, já que sua preocupação inarredável é a pessoa humana. Acompanhou, nesse dispasão, a legislação brasileira de Comércio Justo, por intermédio da Portaria MTE nº 2.060/2014, que veio na esteira dos produtos orgânicos. Com isso, vigoram - atualmente - três tipos de certificação: por auditoria (externa), participativa e controle social (não certificação).

A presente investigação, sob tal pano de fundo, defronta-se com o seguinte problema: as certificações denominadas participativa e controle social - especialmente no âmbito do Comércio Justo - acompanham os valores e as normas de uma emergente sociedade transnacional? Tendo por temática central as espécies de certificação, inclusive utilizadas pela Portaria MTE $n^{\circ} 2.060 / 2014$, os seguintes objetivos foram perseguidos para responder à demanda de pesquisa: identificar o fenômeno do Greenwashing e seu contraponto no consumismo; descrever as certificações dos produtos orgânicos que influenciaram a normatização do Comércio Justo no Brasil; contrastar a tendência da certificação participativa e do controle social do Comércio Justo, na qualidade de características de uma emergente sociedade transnacional.

A temática justifica-se, pois se intensificam as discussões acerca do lançamento de 
uma Rede Brasileira de Comércio Justo. Com isso, o desdobramento do Cadastro Nacional de Empreendimentos Econômicos Solidários (CADSOL) exigirá procedimentos claros acerca do uso de um selo nacional de Comércio Justo, além de discussões sobre a conveniência das certificações atualmente existentes.

As reflexões teóricas que escoram a investigação do binômio consumismo e sustentabilidade valeram-se de Zygmunt Bauman, Gilles Lipovetsky e Boaventura de Souza Santos, além dos estudos de reconhecidas instituições como a World Wide Found for Nature (WWF) e a Market Analysis. A legislação do Ministério da Agricultura, Pecuária e Abastecimento (MAPA), por sua vez, trilhou a análise sobre as certificações de produtos orgânicos que capitaneiam outras certificações. O olhar de Christian Jacquiau e Van Der Hoff serviu à compreensão do Comércio Justo internacional, enquanto Euclides Mance e Fabíola Zerbini auxiliaram na compreensão da formação de redes que sustenta a lógica do Comércio Justo brasileiro.

O método utilizado foi o crítico indutivo, com avaliação de dados de maneira qualitativa e a análise de tabelas de forma quantitativa. Os meios foram majoritariamente bibliográficos, com destaque para consagradas obras doutrinárias. Relatórios institucionais e legislação federal também serviram de meio investigativo. A legislação teve tratamento pelo método hermenêutico gramatical. Quanto aos fins, a pesquisa apresentou-se de cunho descritivo e explicativo. Os resultados foram apresentados em forma de textos.

\section{Consumismo e Greenwashing: causa e efeito para consumo sem culpa na sociedade transnacional}

O Relatório Planeta Vivo - 2014, publicado pela Rede WWF (2016), é categórico ao afirmar que há mais de 40 anos, a humanidade exerce uma demanda sobre a Natureza, insuportável ao planeta. A situação torna-se ainda mais agravante ao perceber que a capacidade de reposição à devastação vem diminuindo. "Seria necessária a capacidade regenerativa de 1,5 Terra para fornecer os serviços ecológicos que usamos anualmente" (WWF, 2016), ou seja, os nefastos efeitos são evidentes: diminuição nos recursos naturais e acumulação de resíduos no habitat. Ainda nessa senda, o Relatório informa que o estado atual da biodiversidade do planeta se agrava, tendo em vista que o Índice do Planeta Vivo, responsável por medir as tendências de milhares de populações de vertebrados, constatou que "diminuiu $52 \%$ entre 1970 e 2010 [...] a quantidade de mamíferos, aves, répteis, anfíbios e peixes em todo o planeta" (WWF, 2016). 
A partir desses alertas e da crescente preocupação ambiental, surgiram diversas iniciativas que prometiam cuidado com o meio ambiente, dentre as quais os selos de sustentabilidade, que representam um elo entre produtor e consumidor e identificam produtos que não causam (ou causam menos) impactos ao meio ambiente. Sob uma identificação visual, trata-se de um diagrama informativo para bens produzidos no âmbito das especificações ambientais. A iniciativa tem origem principalmente na Europa, tendo recebido impulso de Organizações Não-Governamentais (ONGs). No Brasil, existem inúmeras exemplos dessa natureza, estimando-se em torno de 600 selos verdes, grande parte adicionada pelas próprias empresas sem uma auditoria ou análise isenta (JACOB, 2016).

Paralelamente à iniciativa ambientalista outro fenômeno ganharia repercussão: o consumismo. Entre os estudiosos do fenômeno, está o sociólogo polonês Zygmunt Bauman (2008, p. 41), na obra já considerada clássica da área 'Vida Para Consumo - A transformação das pessoas em mercadoria', na qual se retrata o binômio consumo e consumismo. Na ótica do autor, o fenômeno do consumo "tem raízes tão antigas quanto os seres vivos [...] é parte permanente e integral de todas as formas de vida [...]”. Mas, enquanto o consumo constitui uma característica e ocupação de todos os seres humanos enquanto indivíduos, o consumismo é um "atributo da sociedade" (BAUMAN, 2008, p. 42). O referido autor defende que 'consumismo' se realiza quando o consumo assume o papel-chave que na sociedade de produtores era exercido pelo trabalho. Dessa maneira, o consumismo passa a ser central quando:

[...] a capacidade profundamente individual de querer, desejar e almejar deve ser, tal como a capacidade de trabalho na sociedade de produtores, destacada ('alienada', o termo aqui empregado não em conotação pejorativa) dos indivíduos e reciclada/reificada numa força externa que coloca a 'sociedade de consumidores' em movimento e a mantém em curso como uma forma específica de convívio humano, enquanto ao mesmo tempo estabelece parâmetros específicos para as estratégias individuais de vida que são eficazes e manipula as probabilidades de escolha e conduta individuais. (BAUMAN, 2008, p. 42).

O consumismo também é abordado por Lipovetsky (2007, p. 7) ao frisar que o melhorviver "tornou-se uma paixão das massas, o objetivo supremo das sociedades democráticas, um ideal exaltado em cada esquina. Parece que quase nada mudou". Nesse sentido, completa:

No entanto, nas duas últimas décadas, surgiu uma nova 'convulsão' que pôs fim à boa velha sociedade de consumo, transformando tanto a organização da oferta como as práticas quotidianas e o universo mental do consumismo moderno: a revolução do consumo sofreu, ela própria uma revolução. Uma nova fase do capitalismo de consumo teve início: trata-se precisamente da sociedade de hiperconsumo. (LIPOVETSKY, 2007, p. 07-08) 
É Boaventura de Souza Santos (2005, p. 35), contudo, que vivazmente verifica uma face mais amarga da importância do consumo na sociedade globalizada, quando o "conceito de consumidor substitui o de cidadão e o critério de inclusão deixa de ser o direito para passar a ser a solvência". O consumidor, destarte, ganha face e se apercebe responsável (com direitos e deveres) por suas iniciativas.

Consumismo e preocupação ambiental passaram a criar iniciativas que assegurassem ao consumidor a 'certeza' de que a aquisição de produtos não criaria danos aos ecossistemas. Tudo para deixar o consumidor com a consciência tranquila no seu ímpeto de compras. $\mathrm{O}$ mercado sabia disso. Segundo a Market Analysis (2016), no Brasil, no período entre 2005 e 2010, a quantidade de produtos que se autodeclaravam "verdes" cresceu quase cinco vezes $(478 \%)$ e o número total de embalagens com sinais e mensagens indicando posturas simpáticas com o meio ambiente disponíveis para o consumidor cresceu três vezes (296\%). Em 2010, a pesquisa feita a respeito de selos verdes identificou 408 produtos, mas, quase cinco anos depois, esse número tinha alcançado 2.358. Na primeira edição, os produtos apresentaram 781 apelos visuais (através de imagens, desenhos, declarações escritas ou símbolos), em 2015 já eram 3.089 apelos no total (MARKET ANALYSIS, 2016).

Em que pesem as certificações legítimas, nesse interesse pela sustentabilidade como estratégia de venda nasciam também as práticas enganosas, fazendo com que os selos se tornassem farsas, fenômeno conhecido como Greenwashing. O termo literalmente significa 'lavagem verde' e vem na esteira de outro conceito o Greenmarketing. O termo Greenmarketing surgiu nos anos 70 quando a American Marketing Association (AMA) promoveu um Workshop para discutir o impacto do marketing sobre o meio ambiente. Naquela ocasião, gestores de várias áreas estavam convencidos não ser mais possível planejar o Marketing sem incluir ações de Responsabilidade Social e Ambiental (PLANETA AZUL, 2016). Duvidosas, contudo, sempre foram as reais estratégias que essas 'ações corporativas', de fato, iriam empreender.

Ribeiro (2016) em artigo sobre o assunto se indaga: "como é possível um equilíbrio entre a produção e o consumo dos bens, de forma que o meio ambiente não seja atingido? É plausível uma proposta de tal natureza?" Nesse estudo, a autora traz a lume suas preocupações quanto à relação existente entre o fenômeno do consumismo e o chamado consumidor verde.

Como fruto do desenvolvimento capitalista, a mídia se transforma no canal ideal para a divulgação e instauração de novos produtos e também de novas formas de comportamento e necessidades que surgem motivadas pela publicidade. [...] A eterna insatisfação é a mola mestra do mecanismo que faz com que os consumidores busquem, a cada dia, novas alternativas, ainda que se enganando sobre os reais 
motivos da compra. [...] O discurso publicitário, amplamente veiculado em todos os veículos de comunicação, enfatiza que o ato de consumir é uma demonstração de liberdade e autonomia. Quando o discurso da publicidade se aproxima da questão ambiental, então tais mecanismos de sedução e de convencimento da autonomia e responsabilidade individual do consumidor são enfatizados.

Pagotto (2016, p. 44-46) informa que o Greenwashing não é recente e na década de 60 já era utilizado, tendo sido estudado por Jerry Mander, ocasião no qual alertava sobre o oportunismo das empresas em utilizar propagandas inapropriadas ao vender a concepção de sustentabilidade. O fenômeno é importante porque reduz a experiência do consumo, ao invés de fazer refletir sobre os impactos sociais, econômicos e ambientais, simplesmente faz crer que os impactos não existem ou são muito baixos.

O combate ao Greenwashing, portanto, reside também no comportamento do consumidor. Afinal, há uma farsa por trás da tentativa de não impactar o ambiente se que haja um efetivo comportamento harmônico à manutenção dos ecossistemas, tanto no que se refere ao produtor quanto ao consumidor. O Greenwashing traz muito mais do que um estelionato em forma de certificação, gerando dúvidas nos procedimentos e critérios estabelecidos. Tratase de mais uma crise da modernidade pautada pela esperança que terceiro (empresa auditora independente), detentor do conhecimento, seja o único capaz de assegurar a certeza do bem viver. É nesse ponto que se acredita em uma sociedade transnacional que possa, mediante iniciativas inovadoras, assumir novas posturas. É nesse sentido que se defende a utilização da certificação participativa e controle social, pois permitem que produtor e consumidor também tomem para si a responsabilidade do controle, sem transferir a terceiro esse elo de confiança.

\section{Certificação por Auditoria, Certificação Participativa e Controle Social}

O Greenwashing, como se verificou no item anterior, mais que uma fraude, revela a obrigação do consumidor em participar do processo de sustentabilidade. Quando o consumidor vai comprar um produto dito 'verde', procura-se na embalagem o selo que comprova sua procedência. Esse é o elo mágico que viabiliza um consumo sustentável e é a certificação que deve assegurar a confiança no processo. As diferentes propostas de sustentabilidade possuem suas próprias regras de certificação, assim, produtos orgânicos, produtos agroecológicos, madeiras, pesca, economia solidária, comércio justo, entre outros, criaram seus próprios mecanismos de certificação para balizar as relações de consumo que se propõem sustentáveis. 
Essa concepção de certificar produtos possui origem histórica na França, no início do século 20, ocasião na qual pequenos produtores de vinho passaram a diferenciar sua bebida daquela produzida em larga escala por processos industriais. Sob tal lógica, emergiram outras propostas, passando - principalmente - a ser uma exigência do mercado. Essa situação fez que o fabricante de macarrão, por exemplo, quisesse certificar que sua massa era feita de ovos (e não de corantes), entre outras múltiplas situações. Na esteira dessa tendência, houve proliferação de selos nas embalagens. (IBASE, 2016)

No intuito de traçar visão panorâmica sobre o assunto, passa-se a compreensão das distintas certificações, que tem origem na cultura de orgânicos, mas, espraia-se a outras áreas. Com efeito, apesar de as dificuldades existentes, os alimentos orgânicos possuem procedimentos bastante elaborados no âmbito de verificação de conformidade (e, no Brasil, especialmente a partir da prática da Rede Ecovida) e podem ser classificados da seguinte forma: Certificação por Auditoria, Sistema Participativo ou Controle Social. Cada método traz processo e documentação diferentes e, muitas vezes, estão relacionados com o tamanho da propriedade.

O Ministério da Agricultura, Pecuária e Abastecimento (MAPA, 2016a), com base em legislação (Lei $n^{\circ} 10.831$, de 23 de dezembro de 2003, e regulamentação posterior), esclarece que na Certificação por Auditoria há empresas que atuam comercialmente na prestação desse serviço aos produtores individuais e grupos que a solicitam. Nesse caso, a Certificadora contratada deve fazer a avaliação e garantir a conformidade da produção orgânica sob sua responsabilidade. Nesse sentido, essas organizações devem "estar regularmente constituídas para esta atividade e possuir mecanismos de resolução de conflitos, atendimento a denúncias e aplicação de sanções administrativas." (MAPA, 2016a) Além disso, as Certificadoras devem "manter os clientes atualizados quanto às normas vigentes e realizar visitas programadas e sem aviso prévio às unidades, ao menos uma vez ao ano”. (MAPA, 2016a). Cumpre registrar que nesse sistema, os produtores não participam dos processos decisórios sobre certificação.

A Certificação por Auditoria, portanto, consiste em declaração formal de conformidade, no qual terceira entidade assegura ser verídica determinada característica de produto ou serviço. A consistência da informação deve ser emitida por quem tenha autoridade na área de conhecimento solicitada, devendo ser formal, em atenção a critérios previamente definidos. Em síntese, a Certificação por Auditoria segue um estrito procedimento, que se inicia com o cadastramento da Certificadora e na obediência aos ditames legais da área. 
No caso da Certificação Participativa (ou Sistema Participativo de Garantia - SPG) há a formação de um grupo, constituído pela reunião de produtores e outras pessoas interessadas em organizar a sua estrutura básica, que é composta pelos Membros do Sistema e pelo Organismo Participativo de Avaliação da Conformidade (OPAC) (MAPA, 2016a).

\begin{abstract}
Os Membros do Sistema são pessoas físicas ou jurídicas que fazem parte de um grupo classificado em duas categorias, distribuidores, comercializadores, transportadores e armazenadores. Os colaboradores são os consumidores e suas organizações, os técnicos, as organizações públicas e privadas, as que representam as mais diferentes classes e os parceiros (colaboradores) que possam ajudá-los a dar garantia a seus produtos.
\end{abstract}

Nessa circunstância, "todos tomam conta de todos e se visitam, para garantir a qualidade orgânica" (MAPA, 2016a), é quando emerge o protagonismo de produtores e consumidores. Nesse caso, além de não haver o desvio de recursos para empresas certificadoras, não há submissão a um sistema que valoriza o lucro, pautado por interesse comercial das empresas que possuem a certificação como sua principal missão.

Os Organismos Participativos de Avaliação da Conformidade (OPAC) fazem parte do Sistema Participativo de Garantia (SPG) e vão se organizar formalmente enquanto Pessoa Jurídica. Os OPAC corresponderão às empresas certificadoras na certificação por auditoria e, a exemplo dessas, também deverão estar regularmente constituídos, possuir mecanismos de resolução de conflitos, viabilizar o atendimento a denúncias, além de aplicarem sanções administrativas, quando necessário. São os OPAC que avaliam, verificam e atestam que produtos, estabelecimentos produtores ou processadores atendem às exigências do regulamento da produção orgânica. O OPAC assume a responsabilidade formal pelo conjunto de atividades desenvolvidas pelo SPG.

Sempre que houver a certificação, no qual determinado organismo passe a desempenhar decorre a acreditação que, segundo o INMETRO (2016), é uma ferramenta estabelecida em escala internacional para gerar confiança na atuação de organizações que executam atividades de avaliação da conformidade.

Acreditação é o reconhecimento formal por um organismo de acreditação, de que um organismo de Avaliação da Conformidade - OAC (laboratório, organismo de certificação ou organismo de inspeção) atende a requisitos previamente definidos e demonstra ser competente para realizar suas atividades com confiança. Um sistema concebido para acreditar serviços de avaliação da conformidade dos OACs deve transmitir confiança para o comprador e para a autoridade regulamentadora. Tal sistema deve facilitar o comércio através das fronteiras, como buscam as organizações e autoridades em comércio. (INMETRO, 2016) 
No âmbito da Certificação Participativa, merece destaque a experiência da Rede Ecovida, em virtude de já estar consagrada. Essa prática, com mais de 300 produtores no sul do Brasil, assegura desde 1998 a confiança na comercialização de produtos agroecológicos.

\begin{abstract}
O selo Ecovida é obtido após uma série de procedimentos desenvolvidos dentro de cada núcleo regional. Ali ocorre a filiação à Rede, a troca de experiências e verificação do Conselho de Ética. A certificação participativa é uma forma diferente de certificação que além de garantir a qualidade do produto ecológico, permite o respeito e a valorização da cultura local através da aproximação de agricultores e consumidores e da construção de uma Rede que congrega iniciativas de diferentes regiões (REDE ECOVIDA DE AGROECOLOGIA, 2016).
\end{abstract}

Finalmente, existe uma terceira forma que consiste na 'não certificação', denominado Controle Social. Nesse caso, a legislação brasileira abriu uma exceção à obrigatoriedade da certificação de produtos orgânicos, especificamente para atender a venda direta, embora exija a vinculação desses mesmo produtores a uma Organização de Controle Social (OCS). O Decreto $n^{\circ}$ 6.323/07, Art. 2, alínea VIII, define a Organização de Controle Social do seguinte modo:

[...] grupo, associação, cooperativa ou consórcio a que está vinculado o agricultor familiar em venda direta, previamente cadastrado no Ministério da Agricultura, Pecuária e Abastecimento, com processo organizado de geração de credibilidade a partir da interação de pessoas ou organizações, sustentado na participação, comprometimento, transparência e confiança, reconhecido pela sociedade. (BRASIL, 2016b).

Como se expôs, o produtor tem direito apenas a fazer a venda direta ao consumidor ${ }^{1}$, ficando vedada a comercialização para terceiros. Venda direta é a "relação comercial direta entre o produtor e o consumidor final, sem intermediários ou preposto, desde que seja o produtor ou membro da sua família inserido no processo de produção e que faça parte da sua própria estrutura organizacional" (art. $2^{\circ}$, XIX, Decreto $n^{\circ}$ 6.323/07) (BRASIL, 2016b). Por raciocínio inverso, somente o produto certificado (tanto por auditoria, quanto participativa) pode ser comercializado em supermercados, lojas, restaurantes, hotéis, indústrias, internet, entre outras.

Os produtos orgânicos não certificados, por consequência, não poderão utilizar o Selo do Sistema Brasileiro de Avaliação da Conformidade Orgânica. Entretanto, a Lei no 10.831, de 23 de setembro de 2003 (artigo 2º parágrafo primeiro) (BRASIL, 2016a), permite que o agricultor coloque no rótulo do produto, quando existir, ou no ponto-de-venda a

\footnotetext{
${ }^{1}$ A legislação assegura que a venda também seja feita por um outro produtor ou membro da família que participe da produção (desde que faça parte do grupo vinculado à Organização de Controle Social - OCS). O objetivo é garantir que o consumidor final sempre possa elucidar dúvidas sobre o processo de produção.
} 
expressão: "produto orgânico não sujeito à certificação nos termos da Lei no 10.831, de 23 de dezembro de 2003”. (art. 21, parágrafo único, Decreto n 6.323/07) (BRASIL, 2016b).

No Controle Social vigora a denominada Responsabilidade Solidária, pois deve existir uma declaração - assinada por todos os membros do grupo que formam a Organização de Controle Social (OCS) - na qual "os participantes comprometem-se a cumprir os regulamentos técnicos da produção orgânica, responsabilizando se solidariamente nos casos de não cumprimento por algum dos membros" (MAPA, 2016b).

Com efeito, os apelos ambientais estão distribuídos pelo mercado e buscam assegurar a alardeada sustentabilidade. Organizações e consumidores, contudo, podem ir muito além das certificadoras independentes. Segundo a Ecolabel Index (2016), certificações legítimas respondem por apenas $15 \%$ dos produtos comercializados. Tal fato contrasta com a escalada de selos ambientais brasileiros, entre 2010 e 2014: são 41 certificações na atualidade, apresentando um crescimento de $170 \%$ no período (MARKET ANALYSIS, 2016).

\section{Certificação do Comércio Justo: por uma prática transnacional de participação}

O Comércio Justo (Fair Trade) é um movimento transnacional preocupado com a promoção de condições de mercado mais justas entre países consumidores e produtores de países em desenvolvimento. O comércio é considerado Justo em virtude de uma série de fatores, e especialmente porque o preço é justo, vale dizer, cobra os custos de um rendimento digno, ambientalmente responsável e socialmente inclusor. Com isso, há grande atenção não somente com as condições de trabalho do produtor (além da sua família e comunidade, e que deve se estender por toda a cadeia logística), mas, também com o consumidor que pode adquirir bens de forma ética. Trata-se de um raciocínio muito diferente do praticado pelo neoliberalismo, pois no Fair Trade as pessoas são consideradas mais importantes que o lucro.

No âmbito do Comércio Justo existem dois tipos de certificação praticados. O Comércio Justo internacional (Fair Trade), capitaneado pela WFTO, segue a Certificação por Auditoria exclusivamente; enquanto o Comércio Justo nacional adota a Certificação tripartite, à semelhança dos produtos orgânicos, em consonância com a Portaria MTE no 2.060/2014 combinada com o Decreto $n^{\circ} 7.358 / 2010$ e a Portaria MTE $n^{\circ} 1.780 / 2014$. Nesse sentido, passase à compreensão de ambas sistemáticas.

\subsection{Certificação Fairtrade internacional}

No âmbito do comércio internacional, caracterizado pela atuação de grandes empresas e marginalização dos pequenos produtores, o Comércio Justo (Fair Trade) 
representa um contramovimento iniciado na década de 60, decorrente do movimento hippie e da ação de igrejas missionárias. Em 1988, já sob forma mais concreta, a agência holandesa Solidariedade criou o primeiro selo de Comércio Justo denominada Max Havelaar, no qual se colocou à venda o primeiro café oriundo de Comércio Justo procedente do México em supermercados holandeses. A iniciativa Max Havelaar ganhou popularidade e, na continuidade, surgiram iniciativas similares de selos de garantia na Europa, nos Estados Unidos e no Canadá.

Em 1997, diversas organizações alinhadas com a iniciativa Max Havelaar criaram a Fairtrade Labeling Organizations International (FLO), com sede em Bonn (Alemanha), harmonizando critérios e o processo de certificação dos produtos Fairtrade ${ }^{2}$. Em 2002, a FLO lançou um novo selo denominado International Fairtrade Certification Mark. Em 2003, foi criada a FLO-CERT, empresa de funcionamento independente, responsável pela inspeção e certificação de produtores e do comércio.

Na certificação da FLO-CERT o processo inicia a partir de um contato ${ }^{3}$ com essa organização que certifica e realiza os processos de auditoria nos empreendimentos, mediante contratação. O requerente deve estar preparado para cumprir diversas iniciativas expostas nas diretrizes da WFTO, como possuir gestão democrática, transparência nos processos internos, igualdade de tratamento entre os componentes, sustentabilidade, entre outros. Cumpre destacar que, desde o início, o requisitante precisa revelar que possui um comprador interessado, evitando o investimento na Certificação, sem que se concretize a venda.

Feita uma análise prévia dos critérios de certificação, há a emissão de um boleto que dará início à visita e à verificação da adequação da propriedade com as demais exigências. Completa o processo a visita da FLO-CERT nas dependências e a juntada de documentação solicitada pelos auditores. Após análise, o produto passa a contar com o selo Fairtrade. No Brasil, um dos poucos produtos encontrados com o selo Fairtrade é o café da COOPFAM (Cooperativa dos Agricultores Familiares de Poço Fundo e Região que, de maneira cooperada, reúne mais de 320 famílias de pequenos cafeicultores no Sul de Minas Gerais).

Cumpre ponderar, sob outro enfoque, aspectos críticos que esse sistema tem enfrentado. Para Christian Jacquiau (2016), o denominado comércio equitativo tem sofrido

\footnotetext{
${ }^{2}$ Fairtrade escrito junto significa o selo do comércio justo (enquanto Fair Trade, separado, designa o próprio comércio).

${ }^{3}$ Somente produtores que participem de organizações formais, como associações ou cooperativas podem pleitear o certificado, não estando disponível para o agricultor individual
} 
embates, especialmente após a parceria entre a Max Havelaar e a empresa Dagris. A companhia Dagris, que pertencia ao Estado francês foi criada durante a época do colonialismo para explorar o algodão africano. Detentora de um quase monopólio no setor algodoeiro da África Ocidental, a organização que estava em processo de privatização, colocava em risco a produção de pequenos produtores perante as exigências dos seus acionistas. Afinal, o pagamento de um justo preço aos produtores conflitava com a ambição por significativos dividendos.

O conflito de interesses encontrou término quando a Dagris se voltou à proposta do comércio equitativo com a Max Havelaar. "Dos 240 mil pequenos agricultores de algodão produzindo para a sociedade, 3.280 foram selecionados para se beneficiar do sistema Max Havelaar" (JACQUIAU, 2016). A Certificação Max Havelaar, a partir dessa parceria, colocava sob suspeita o selo que tinha fundado todo um movimento social transnacional interessado em promover condições mais justas de comércio. Outras considerações também levaram à decisão da Max Havelaar a certificar o algodão da Dagris, como dívidas e impostos atrasados. Com efeito, na continuidade a associação foi recompensada: "recebeu 610 mil euros do Ministério dos Negócios Estrangeiros francês e 500 mil euros do Centre pour le Développement de la Entreprise (CDE). No total, mais de 1,7 milhão de euros, compreendidas aí todas as subvenções, só no ano de 2004". (JACQUIAU, 2016) Seja como for, a Dagris que era herdeira da companhia colonial espoliadora dos pequenos produtores de algodão continuaria em injusto processo de relação com os produtores. Nesse diapasão, emergiram discussões acerca da certificação, dos processos internos e dos critérios que balizam a utilização do selo. Em síntese, a certificação de Comércio Justo internacional por auditoria externa vem atravessando suspeitas de Fairwashing, no qual a confiança está em jogo.

\subsection{Certificação do Comércio Justo à brasileira}

De outra banda emerge o modelo de Comércio Justo brasileiro. O assunto foi disciplinado por intermédio da Portaria MTE $\mathrm{n}^{\text {o }}$ 2.060/2014, ao instituir os Princípios e Critérios e os mecanismos de Avaliação da Conformidade da Prática de Comércio Justo e solidário e da Gestão e Organização do Sistema Nacional de Comércio Justo e Solidário (SCJS). O Brasil é o único País a cuidar da questão da certificação de Comércio Justo com normas públicas.

Inicialmente, havia o Decreto $\mathrm{n}^{\mathrm{o}} 7.358 / 2010$ (BRASIL, 2016c) que havia criado o Sistema Nacional do Comércio Justo e Solidário (SCJS) e a Comissão Gestora Nacional. Em 
2014, conforme a Portaria MTE $n^{\circ}$ 2.060/2014 (BRASIL, 2016e) foram instituídos os princípios, critérios, sistemas de avaliação de conformidade e mecanismos de gestão.

No que se refere à Certificação, acompanhou-se a metodologia dos produtos orgânicos, dividindo em três metodologias, segundo previsão expressa do artigo $7^{\circ}$ da Portaria MTE $n^{\circ}$ 2.060/2014. "As metodologias de avaliação de conformidade da prática de Comércio Justo e solidário são divididas em três categorias, conforme o tipo de organismo de avaliação da conformidade" (artigo $7^{\circ}$ ), ou seja: a) a metodologia utilizada pelos Organismos Participativos de Avaliação da Conformidade (OPAC) (artigo $8^{\circ}$ ) que espelha a Certificação Participativa, b) os Organismos de Avaliação da Conformidade por terceira parte (OAC $3^{\text {a }}$ Parte) que se referem à Certificação por Auditoria; e, c) os Organismos Coletivos Autogestionários de Controle Social da Conformidade (OCACS) (artigo $10^{\circ}$ ) que dizem respeito ao Controle Social.

Antes mesmo que se passe à análise da Portaria MTE n 2.060/2014, cumpre trazer alguns aspectos pertinentes à Portaria MTE nº 1.780/2014 (BRASIL, 2016 d), instituída em 19 de novembro de 2014, que estabelece o Cadastro Nacional de Empreendimentos Econômicos Solidários (CADSOL). O referido Cadastro objetiva o reconhecimento público dos Empreendimentos Econômicos Solidários (EES) existentes na Rede brasileira, além de viabilizar a esses sujeitos o acesso às políticas públicas nacionais de economia solidária, programas públicos de financiamento, compras governamentais e comercialização de produtos. O Cadastro se efetiva por preenchimento de formulário eletrônico disponibilizado na página da Secretaria Nacional de Economia Solidária (SENAES) e obedece a diversos requisitos para implementação (artigo $1^{\circ}$, da Portaria MTE $n^{\circ} 1.780 / 2014$ ).

O Cadastro é obrigatório aos Empreendimentos Econômicos Solidários para que sejam incluídos no Sistema Nacional de Comércio Justo e Solidário (artigo 4, da Portaria MTE $\mathrm{n}^{\circ}$ 1.780/2014). Há evidente interligação entre os dois dispositivos (veja-se artigo $9^{\circ}$, parágrafo único, da Portaria MTE $n^{\circ}$ 1.780/2014), pois para subsidiar o Conselho Nacional de Economia Solidária na execução das atribuições de criar o CADSOL foi constituída a Comissão Nacional de Cadastro, Informação e Comércio Justo e Solidário. A referida Comissão terá composição baseada no artigo 10 (da Portaria MTE $n^{\circ}$ 1.780/2014) que, em grande medida, repete a Comissão Gestora Nacional prevista pelo Decreto $\mathrm{n}^{\circ}$ 7.358/2010, quando instituiu o Sistema Nacional do Comércio Justo e Solidário (SCJS) e criou a Comissão Gestora Nacional, posteriormente referida no artigo $2^{\circ}$, inciso X e outros, da Portaria MTE nº 2.060/2014. 
No caso da Certificação por Auditoria, a proposta de atuação dos Organismos de Avaliação da Conformidade por terceira parte (OAC $3^{a}$ Parte) não foge à tradicional certificação por inspeção, embora se exija o credenciamento perante a Comissão Gestora Nacional do Sistema. Nesse sentido, os procedimentos são baseados em vistoria externa e independente, mediante contratação formal (artigo $9^{\circ}, \S 1^{\circ}$ ) de OAC que, em sua estrutura organizacional, seja possível perceber uma divisão clara entre as funções de verificação e de decisão final (artigo $9^{\circ}$, $\S 2^{\circ}$ ). Com razão, a decisão final para a emissão do Certificado será feito por um Colegiado da $\mathrm{OAC}$, sem que participe o auditor que realizou a visita e tampouco o Empreendimento que se sujeitou à verificação $\left(\operatorname{artigo~} 9^{\circ}, \S^{\circ}\right.$ ). A OAC terá prazo máximo de 45 (quarenta e cinco) dias da data da visita ao empreendimento para lançar no sistema informatizado do SCJS ou informar via comunicado à Comissão Gestora Nacional (CGN-SCJS) os dados referentes às visitas de avaliação de conformidade feitas nos empreendimentos ou parceiras comerciais sob sua responsabilidade (artigo 12).

A Certificação Participativa será concretizada pelos denominados Organismos Participativos de Avaliação da Conformidade (OPAC), compostos pelos sujeitos do Sistema Participativo de Garantia (SPG) que precisarão firmar entre si um acordo de responsabilidade, no qual deverão ser esclarecidos os critérios e procedimentos a serem adotados. A marcante característica dessa metodologia, conforme a tônica do artigo $8^{\circ}$ reside na credibilidade gerada pelos mecanismos e procedimentos que o controle social venha a desempenhar. Além disso, caberá aos membros integrantes do SPG não somente a participação, como a responsabilidade coletiva e solidária para acompanhar o processo. Não se trata, portanto, do cômodo processo modernista de sujeição a terceiro, supostamente dotado de conhecimento e capacidade para fazer a avaliação. Pelo contrário, em nítido movimento de hipermodernidade, como proposto por Lipovetsky (ano), será necessário o engajamento de seus membros. Ou, no entender de Boaventura de Souza Santos (2005, p. 71), uma globalização de baixo para cima.

Finalmente, o artigo 10 traça diretrizes para o Controle Social por intermédio dos OCACS, vale dizer, organizações formadas por - no mínimo - 3 empreendimentos econômicos solidários, cujos membros assinam e registram compromisso em cartório entre si para estabelecer os mecanismos participativos (artigo 10 ${ }^{\circ}$ ). Esses mecanismos servirão de balizamento para atestar a avaliação de conformidade, pois a metodologia dos OCACS está escorada na credibilidade gerada pelos seus mecanismos de controle social. Mais uma vez, a exemplo da Certificação Participativa, desempenhará papel fundamental a participação e a responsabilidade coletiva e solidária dos seus membros (artigo 10, $\$ 1^{\circ}$ ). O Controle Social propriamente dito deverá ser facilitado pelo OCACS, que incentivará a organização social e o 
exercício da democracia dos empreendimentos participantes, facilitando o acesso às práticas de Comércio Justo e Solidário.

Para que funcione o sistema visando à certificação, os empreendimentos econômicos solidários terão que acompanhar as diretrizes do artigo 11, dentre as quais obediência aos regulamentos técnicos, princípios, diretrizes e critérios estabelecidos no âmbito do SCJS, o consentimento de visitas de verificação, o fornecimento de informações precisas e nos prazos previamente estabelecidos, entre outros.

O Certificado de Conformidade será emitido por OAC credenciada, autorizando os empreendimento econômico solidário (EES) e os parceiros comerciais, que atenderem ao disposto no regulamento do Sistema Nacional de Comércio Justo e Solidário (SCJS), a usar o 'Selo CJS' ou marca de espaço de comercialização solidária (ECOS) do SCJS (artigo 2º X). A partir de então, o Empreendimento passará a ser certificado.

Para Fabíola Zerbini (2016), não se trata de construir um sistema puro de monitoramento e certificação de cadeias justas de comercialização. Deseja-se estimular tais cadeias como mecanismos de fortalecimento da produção, comercialização e consumo solidários. O sistema brasileiro constitui-se em um processo tanto político quanto econômico. Político, pois institucionaliza publicamente o potencial de transformação social que o Comércio Justo tem, na medida em que se impõe como alternativa (de longo prazo) à exclusão e às injustiças geradas pelas transações comerciais convencionais. E econômico, pois identifica e fortalece relações comerciais que já são concretas, contudo, sob uma lógica inclusora de camadas da população que historicamente viviam à margem do sistema (ZERBINI, 2016).

Nota-se que o modelo brasileiro traz valores da sociedade transnacional emergente, pois apresenta a possibilidade de envolver ativamente os sujeitos da relação de consumo: produtores, certificadores participantes e consumidores. Não há necessidade de sujeição passiva aos certificadores externos, verdadeiros estranhos que, sob argumento de serem detentores do saber, arvoram-se no poder da certificação. Com isso, não se defende que as certificadoras independentes sejam, por si, um mal. Contudo, em processos mais amadurecidos de certificação e em harmonia ao fenômeno da transnacionalidade, as organizações podem ser donas das próprias trajetórias.

Mance (2002, p. 71) já havia esclarecido que quando se fala em uma nova ordem mundial "estamos supondo a lógica da diversidade [...] enfatizamos a possibilidade de processos de organização a partir da livre decisão das pessoas de proverem simultaneamente o seu bemviver e o das sociedades em laços solidários de realimentação." Nesse diapasão, 
também o alerta de Van Der Hoff $(s / d)$ sobre a impossibilidade de ser contra o mercado, entretanto, o consumidor precisa perceber que no mercado atual se corre perigo.

A providência que aparentemente regula tudo rumo ao bem comum morre por completo quando vemos que o bem comum não acontece. É por isso que o Mercado Justo é um Mercado de regulação: pagamento devido conforme o trabalho, ser dono sobre o produto até o consumidor, produzir coisas que necessitamos para viver bem e saudável e dar novamente ao consumidor a liberdade de tomar decisões próprias e justas no mercado. (VAN DE HOFF, $s / d$ ).

Essa também é a sociedade que vislumbra Boaventura de Souza Santos (2005, p. 67), baseada em resistência que consiste em transformar trocas desiguais em trocas de autoridade partilhada, traduzindo-se em lutas contra a exclusão e a inclusão subalterna. As atividades cosmopolitas referidas pelo autor incluem movimentos no interior das periferias dos sistema mundial; redes de solidariedade transnacional não desigual entre o Norte e o Sul; organizações não governamentais (ONGs) transnacionais de militância anticapitalista; entre outros.

Nessa senda, a preocupação ambiental representa uma das transformações mais significativas dessa emergente sociedade, tendo na sustentabilidade seu mote de verdadeira superação e nas certificações participativas ou no controle social um novo 'contrato social' que pode, por conta de seus valores intrínsecos, transbordar as fronteiras e amalgamar um legítimo Comércio Justo.

\section{Conclusão}

Além do consumismo, há uma sociedade, com valores transnacionais, apta a assumir suas responsabilidades, em movimento contrário à globalização hegemônica. Nesse sentido, emergiram as propostas de certificação participativa e de controle social, autênticos instrumentos para a construção de um novo modelo.

No âmbito do Comércio Justo internacional, em que pese o esforço na composição de um mercado inclusor, percebe-se um esgotamento do modelo pautado pelas auditorias externas, mesmo no âmbito da FLO-CERT ou da Max Havelaar. É cada vez mais determinante, que a diminuição dos grupos sociais vitimados pelas trocas desiguais seja uma operação conjunta de uma sociedade transnacional ativista. O desejo de transferir a certificação para um auditor terceiro e estranho perde força, inclusive sob suspeita de aceitar os valores neoliberais tão combatidos na proposta original. É nesse sentido que o Greenwashing retrata não somente um falseamento da certificação, mas, um isolamento das motivações de sustentabilidade na origem. 
Sob inspiração da agroecologia e especialmente da experiência da Rede Ecovida foi possível permitir que o modelo do Comércio Justo brasileiro trouxesse um inédito modelo à certificação nacional. Com isso, a Portaria MTE nº 2.060/2014 incluiu além da auditoria externa, também a certificação participativa e o controle social. Apesar de não se esgotar na certificação, o Comércio Justo brasileiro trouxe a possibilidade de um movimento contra hegemônico à globalização, na qual uma sociedade transnacional tem a chance de ser sujeito da sua própria história.

Vive-se um modelo comercial em transição, pois apesar das velhas estruturas do comércio mundial verifica-se a aurora de um novo modelo, no qual o consumidor deixa de ser expectador passivo das relações de troca e na qual o ato de consumo pode se revelar um ato político de escolha na construção das estruturas de uma sociedade transnacional. O Comércio Justo, apesar da turbulência da inevitável certificação, faz crer sobre a possibilidade de alcançar justiça nas relações de troca e a transformação da exploração em solidariedade mundial.

\section{Referências}

BRASIL. Lei no 10.831, de 23 de dezembro de 2003. Disponível em:

<http://www.planalto.gov.br/ccivil_03/LEIS/2003/L10.831.htm> Acesso em: 16/03/2016a.

BRASIL. Decreto $\mathbf{n}^{0}$ 6.323, de 27 de dezembro de 2007. Disponível em:

<http://www.planalto.gov.br/ccivil_03/_ato2007-2010/2007/Decreto/D6323.htm> Acesso em: $16 / 03 / 2016 b$.

BRASIL. Decreto $\mathbf{n}^{\mathbf{0}} \mathbf{7 . 3 5 8}$, de 17 de novembro de 2010 - Institui o Sistema Nacional do Comércio Justo e Solidário - SCJS, cria sua Comissão Gestora Nacional, e dá outras providências. Disponível em: <http://www.planalto.gov.br/ccivil_03/_Ato20072010/2010/Decreto/D7358.htm> Acesso em: 11/03/2016c.

BRASIL. Portaria MTE no 1780, de 19 de novembro de 2014 - Institui o Cadastro de Empreendimentos Econômicos Solidários - CADSOL. Disponível em: < http://portal.mte.gov.br/data/files/FF80808148EC2E5E014A05E223A352DC/Portaria-

GM\%20n\%C2\%BA\%201780,\%20de\%2019.11.2014\%20-\%20CADSOL.pdf.> Acesso em: $11 / 03 / 2016 \mathrm{~d}$.

BRASIL. Portaria MTE $\mathbf{n}^{\mathbf{0}}$ 2.060, de 30 de dezembro de 2014 - Institui os princípios, critérios, sistema de avaliação de conformidade e os mecanismos de gestão do Sistema Nacional de Comércio Justo e Solidário - SCJS. Disponível em: 
<http://pesquisa.in.gov.br/imprensa/servlet/INPDFViewer?jornal=1\&pagina=53\&data=08/01/ 2015\&captchafield=firistAccess $>$ Acesso em: 11/03/2016e.

ECOLABEL INDEX. All ecolabels. Disponível em: <http://www.ecolabelindex.com> Acesso em: 25/03/2016.

IBASE (Instituto Brasileiro de Análises Sociais e Econômicas). Comercialização e Certificação Participativa. Disponível em:

$<$ http://www.fbes.org.br/index2.php?option=com_docman\&task=doc_view\&gid=1362\&Itemi $\mathrm{d}=8>$ Acesso em: 16/03/2016.

JACOB, Daniele de Campos. Sustentabilidade empresarial. Revista Científica Eletrônica da FAIT. Disponível em:

<http://fait.revista.inf.br/imagens_arquivos/arquivos_destaque/g6Q5pPNIUeEgSiO_2015-131-14-53-59.pdf> Acesso em: 11/03/2016.

JACQUIAU, Christian. Ambiguidades do comércio equitativo. Le Monde Diplomatique Brasil. Disponível em: <https://www.diplomatique.org.br/print.php?tipo=ac\&id=2132> Acesso em: 22/03/2016.

LIPOVETSKY, Gilles. A Felicidade Paradoxal: Ensaio sobre a sociedade de hiperconsumo. Lisboa: Edições 70, 2007.

MAPA (Ministério da Agricultura, Pecuária e Abastecimento). Certificação. Disponível em: <http://www.agricultura.gov.br/portal/page/portal/Internet-MAPA/paginainicial/desenvolvimento-sustentavel/organicos/regularizacao-producao-organica/certificacaopor-auditoria-rpo> Acesso em: 16/03/2016a.

MAPA (Ministério da Agricultura, Pecuária e Abastecimento). Controle social na venda direta ao consumidor de produtos orgânicos sem certificação. Disponível em: <http://www.agricultura.gov.br/portal/> Acesso em: 14/03/2016b.

MARKET ANALYSIS. Greenwashing afeta 8 em cada 10 produtos vendidos no Brasil. Relatório. <http://marketanalysis.com.br/publicacoes/greenwashing2014/> Acesso em: $11 / 03 / 2016$

PAGOTTO, Érico Luciano. Greenwashing: os conflitos éticos da propaganda ambiental. Dissertação de Mestrado/USP. São Paulo, 2013. Disponível em: < http://www.teses.usp.br/teses/disponiveis/100/100134/tde-22072013-141652/pt-br.php > Acesso em: 22/03/2016

PLANETA AZUL. Green Marketing. Disponível em: <http://www.planetazul.pt/edicoes1/planetazul/palavra.aspx?id=16956> Acesso em: $11 / 03 / 2016$. 
REDE ECOVIDA DE AGROECOLOGIA. Certificação participativa em rede: um processo de certificação adequado à agricultura familiar agroecológica no sul do Brasil. Disponível em: <https://cepagroagroecologia.wordpress.com/tag/rede-ecovida/> Acesso em: 25/03/2016.

RIBEIRO, Rita Aparecida da Conceição. Das estratégias do Greenmarketing à falácia do Greenwashing: a utilização do discurso ambiental no design de embalagens e na publicidade de produtos. V Encontro Nacional da Anppas. Disponível em: < http://www.anppas.org.br/encontro5/cd/artigos/GT8-645-626-20100825115643.pdf> Acesso em: 11/03/2016.

SANTOS, Boaventura de Souza. Os processos de globalização. In: SANTOS, Boaventura de Souza (Org.) A Globalização e as Ciências Sociais. São Paulo: Cortez, 2005.

VAN DER HOFF, Frans. El corazón del comercio justo. México: manuscrito, $s / d$.

ZERBINI, Fabíola. Conheça o SNCJS. Disponível em: < http://facesdobrasil.org.br/sistemanacional-de-comercio-justo-e-solidario/conheca-o-sncjs > Acesso em: 13/03/2016.

WWF (World Wide Found for Nature). Relatório Planeta Vivo - 2014. Disponível em: <http://www.wwf.org.br/natureza_brasileira/especiais/relatorio_planeta_vivo/> Acesso em: 13/03/2016. 